\title{
Basic and Clinical Pharmacology of the Acetylcholine Receptor: Implications for the Use of Neuromuscular Relaxants
}

\author{
JA Jeevendra Martyn \\ Department of Anaesthesia, Massachusetts General Hospital and Shriners Burns Institute,
and Harvard Medical School, Boston, MA, USA
}

(Reccived for publication on November 14, 1994)

\begin{abstract}
Multiple factors alter the interaction of muscle relaxants with the neuromuscular (NM) junction. This review focused on the aberrant responses caused, principally, by alterations in acetylcholine receptor (AChR)s. It should be emphasized that prejunctional and post $\mathrm{AChR}$ factors also may alter sensitivity to muscle relaxants and also cause functional changes, including muscle weakness. The pharmacokinetic and pharmacogenetic factors which cause aberrant responses have not been discussed. Many pathological states increase or decrease AChRs and this has been enumerated in Table 1. Increased AChRs is associated with resistance to the NM effects of nondepolarizing (ND)MR. With proliferation of AChR, the exaggerated release of potassium with depolarization from succinylcholine ( $\mathrm{SCh}$ ) can be attributed to increased AChR number; qualitative changes in AChR number may also play a role. Preliminary studies using potassium channel inhibitors indicate that potassium channels do not play a major role in the hyperkalimic response to SCh. During acute organophosphorus poisoning, SCh should be avoided because its metabolic breakdown would be impared; ${ }^{1}$ the requirement for NDMR may be increased because of increased competition with high leels of $\mathrm{ACh}$ at the neuromuscular junction. With the chronic presence of $\mathrm{ACh}$ at the neuromuscular junction there would be down regulation and the responses would be similar to that seen in myasthenia gravis. All of these responses to SCh and NDMR which are associated with concomitant changes in $\mathrm{AChR}$ are analogus to drug-receptor interactions observed in other biological systems. (Keio I Med 44 (1): 1-8, March 1995)
\end{abstract}

Key words: acetylcholine receptor, neuromuscular agents, succinylcholine, d-tubocurarine, pharmacology

Neuromuscular (NM) relaxants are used in the emergency room, operating room and in the Intensive Care Unit to effect muscle relaxation for intubation, for surgery as well as for effective mechanical ventilation with positive end expiratory pressure. Shortly after the introduction of NM relaxants to clinical practice in 1942, it became apparent that certain pathological states and/or genetic factors could be associated with both hyper- and hypo-sensitivity to both agonist-type or depolarizing, and antagonist or nondepolarizing (ND)MR. ${ }^{2}$ (Depolarizing relaxants such as succinylcholine, $\mathrm{SCh}$ and decamethonium should be considered acetylcholine receptor (AChR) agonists since their pharmacological actions are like acetylcholine ( $\mathrm{ACh}$ ) in that, at least initially, they stimulate AChRs. NDMRs such as tubocurarine (dTC) and vecuronium are competitive antagonists of the AChRs because they competitively inhibit the effects of $\mathrm{ACh}$ ). Cardiac arrest, following succinylcholine was reported to occur in certain patients. ${ }^{3}$ The availability of quantitative assays for drug concentrations and receptors, together with electrophysiologic and immunologic techniques, have enabled investigators to correlate alterations in sensitivity of NM relaxants to pharmacokinetic, pharmacodynamic or to pharmacogenetic causes. Pharmacokinetics refers to changes in distribution, clearance and/ or elimination of a drug. Pharmacodynamics examines the relationship of a drug concentration (in blood or tissue) to pharmacologic effects and, therefore, documents the sensitivity of the target organ to a drug. Pharmacogenetics is the study of the role of genetics (and environment) in variations to drug response. Examples of genetically mediated abnormal response to muscle relaxants include prolonged recovery, contracture or malignant hyperthermic response to succinylcholine. This review will specifically focus on the qualitative and quantitative changes in the nicotinic acetylcholine recep-

Presented at the 884th Meeting of The Keio Medical Society in Tokyo, November 16, 1994.

Reprint requests to: Dr JA Jeevendra Martyn, Department of Anaesthesia, Massachusetts General Hospital, Fruit Strect, Boston, MA (12114, USA 
tors (AChRs) at the muscle membrane and its relationship to NM relaxant sensitivity. Pathological states, including iatrogenic factors and the molecular mechanisms, which may play a role in these AChR changes, will be also discussed. Pharmacokinetic and pharmacogenetic causes of aberrant responses to NM relaxants is not within the scope of this paper.

\section{Basic Biology and Pharmacology of the AChRs}

The classical pharmacological dogma regarding upregulation (increased numbers) and down-regulation (decreased numbers) of receptors, and its relationship to agonists and antagonists responses can be invoked to explain the AChR-mediated abnormal responses to muscle relaxants. ${ }^{3,4}$ It must be emphasized, however, that in addition to AChR changes, prejunctional (nerverelated) and postjunctional (muscle-related) changes can also affect NM transmission and sensitivity to muscle relaxants. The receptor theory proposes that up-regulation of receptors is associated with increased sensitivity to agonists and decreased sensitivity to antagonists. ${ }^{4}$ This upregulation and increased sensitivity to agonists may result in lethal hyperkalemia when SCh-induced depolarization causes massive potassium efflux through the upregulated AChRs. Down-regulation is associated with decreased sensitivity to agonists (SCh) and increased sensitivity to antagonists (e.g. dTC). Clinical conditions in which there is an increase or decrease in AChR numbers are indicated in Table 1.

These aberrant agonist and antagonists responses related to up- and down-regulation of AChRs is complicated by the potential presence or absence of another isoform of AChR at the muscle membrane. ${ }^{5}$ The AChRs present in the normal, adult, innervated muscle are considered mature receptors. A mature or junctional receptor is formed of five subunit proteins termed $\alpha, \beta, \epsilon$, and $\sigma$ subunit in the ratio of $2: 1: 1: 1$. When there is deprivation of neural influence, as in denervation, a new form of receptor with a subunit composition of $\alpha, \beta, \gamma$ and $\sigma$ in

Table 1 Pathological States Associated with Changes in Acctylcholine Receptors

\begin{tabular}{lc}
\hline \hline $\begin{array}{l}\text { Increased AChRs with Resistance } \\
\text { to NDMR and Hyperkalcmia } \\
\text { to Agonists }\end{array}$ & $\begin{array}{c}\text { Decreased AChRs with } \\
\text { Sensitivity to NDMR } \\
\text { and Resistance to Agonists }\end{array}$ \\
\hline $\begin{array}{l}\text { Any neurlogic deficit } \\
\text { Dircet muscle trauma } \\
\text { Thermal trauma }\end{array}$ & $\begin{array}{l}\text { Myasthenia gravis } \\
\text { Organophosphorus poisoning } \\
\text { Chronic anticholincsterac } \\
\text { treatment }\end{array}$ \\
$\begin{array}{l}\text { Disuse atrophy } \\
\text { Critical illncss }\end{array}$ & \\
Prolonged use of NDMR & \\
Severe infection & \\
\hline
\end{tabular}

the ratio of 2:1:1:1 is synthesized (Fig 1). The immature receptors are no longer localized to the end-plate region but are inserted throughout the muscle membrane into junctional and extrajunctional areas. The specific radioligand of AChRs of the skeletal muscle, $\alpha$-bungarotoxin $(\alpha$-BT), does not differentiate between mature junctional and immature AChRs. Electrophysiologic, molecular biologic and immunologic (monoclonal antibody) techniques, however, can distinguish them. ${ }^{5}$ The functional and pharmacological characteristics differ between the mature and the immature AChRs and has been attributed to the changes in subunit composition of the two isoforms. The channel conductance is smaller, and open channel time longer in the immature AChRs. Agonists, such as $\mathrm{ACh}$, decamethonium, and $\mathrm{SCh}$ depolarize immature receptors more easily. The potency of competitive antagonists such as dTC is also altered; low concentrations of dTC effectively antagonize the actions of ACh in the mature receptors. In contrast, the immature receptors are less sensitive to the antagonistic effects of dTC. Similarly higher concentrations of cholinergic ligands (e.g. dTC, decamethonium) are required to prevent the binding of $\alpha$-BT to extra junctional receptors. The apparent disossociation constant (Kd) for dTC binding to junctional receptor was $4.5 \times 10^{-8} \mathrm{M}$, whereas the value for extrajunctional receptor was $5.5 \times 10^{-7} \mathrm{M}$. Recent studies of Gu $e t$ al, where mature and immature AChRs were expressed in COS cells, however, have queried whether in fact these differences in ligand in affinity exist. ${ }^{3}$

Thus the altered sensitivity to depolarizing (agonists) and nondepolarizing (antagonists) relaxants may be related to changes, in quality and quantity of AChRs, in affinity for ligands and changes in electrophysiological properties. Additional factors that may contribute to this altered sensitivity include decreased acetylcholinesterase activity

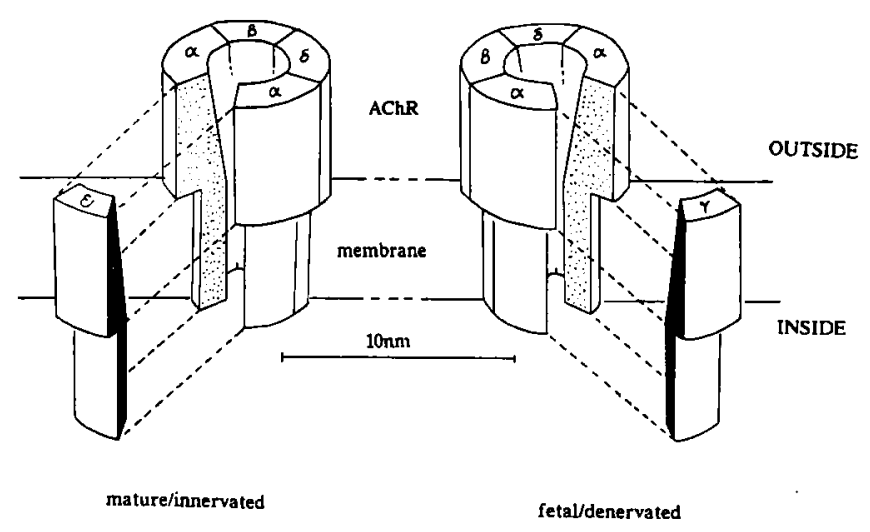

Fig 1 AChR channels with subunits $(\alpha, \beta, \epsilon$ and $\sigma$ or $\alpha, \beta, \gamma$ and $\sigma)$ around the central cation channel. The mature receptor is seen in innervated muscle while the immature receptor is secn in denervated or fetal tissue. The binding of $\mathrm{ACh}$ results in opening of the channel. The mean open channel times differ between the two types of AChR. 
and partial intrinsic agonist activity present in some of the competitive antagonists (e.g. dTC).

\section{Clinical Syndromes Associated with Upregulation of AChRs}

\section{Denervations syndromes}

The relationship of upper or lower motor neuron injury to succinylcholine-induced hyperkalemia has received attention in many reports. ${ }^{6,7}$ More recent studies have documented that upper motor neuron injury (e.g. stroke, transection of the spinal cord) results in resistance to the effects of NDMR in the affected limb. ${ }^{8}$ The appearance of denervation-like changes in the presence of an anatomically intact motor nerve supports the concept that even following central denervation, there is transynaptic degeneration of the $\alpha$-motor neurons probably related to deprivation of trophic factors or inputs that are normally received from descending motor pathways. Of note, is the finding that decreased sensitivity to competitive antagonists could be observed not only on the affected (stroked) side but also on the unaffected (normal) side. ${ }^{3}$

Complete transection of a motor nerve results in Wallerian degeneration. Although the response to succinylcholine could be studied in a muscle that has been damaged in this fashion, the sensitivity to NDMR can not be studied because nerve-mediated twitch tension cannot be elicited. The hypothesis that lower motor neuron injury, with associated proliferation of AChRs, induces resistance to NDMR was tested following partial denervation. ${ }^{9}$ The left gastrocnemius was denervated by a $75-80 \%$ lesion of the sciatic nerve. The effective dose for $95 \%$ twitch depression was studied in the denervated gastrocnemius and compared to the contralateral undenervated and sham-injured (control; gastrocnemius muscles approximately 2 weeks after injury. The dose and plasma concentrations of dTC for twitch inhibition of the denervated leg was significantly higher than contralateral or sham-operated muscles. There was a significant correlation $\left(\mathrm{R}^{2}=0.73\right)$ between dose and AChR number. One can therefore conclude that following partial denervation (and possibly during reinnervation) of a lower motor neuron injury there is resistance to NDMR on that side but the contralateral neuromuscular responses are unaffected.

\section{Burns}

Burned and denervated patients share a hypersensitivity response to $\mathrm{ACh}$ or $\mathrm{SCh}$ and hyposensitivity response to of NDMR. ${ }^{3}$ The hypothesis that an upregulation of AChRs occurs at the muscle membrane at sites distant from the burn has been tested in the rat after an approxi- mate $45 \%$ body surface area burn. ${ }^{10}$ Increased AChRs were present as early as 10 days after burn and this persisted even at 28 days (Fig 2), particularly in the animals with burn injury greater than $45 \%$ body surface area burn. Other studies have confirmed an association $\left(R^{2}=0.65, R=0.81\right)$ between effective dose for $d T C$ and changes in AChR concentration in the gastrocnemius (Fig 3). ${ }^{11}$ Many investigators, both in animal and human studies, have now confirmed the resistance to NDMR following burns and increases in AChRs associated with burn injury. ${ }^{12.13}$

\section{Immobilization and atrophy}

Several models of immobilization have been studied and include application of plaster cast to one or more limbs, application of anesthetics or toxins to nerve or muscle and pinning of joints. The state of immobilization contrasts with denervation in that there is no direct damage to cord or nerve roots; the muscle fibers remain innervated. Immobilization is comparable but lesser in magnitude to denervation syndromes, in that there is muscle atrophy and increased $\mathrm{ACh}$ or $\mathrm{SCh}$ sensitive area

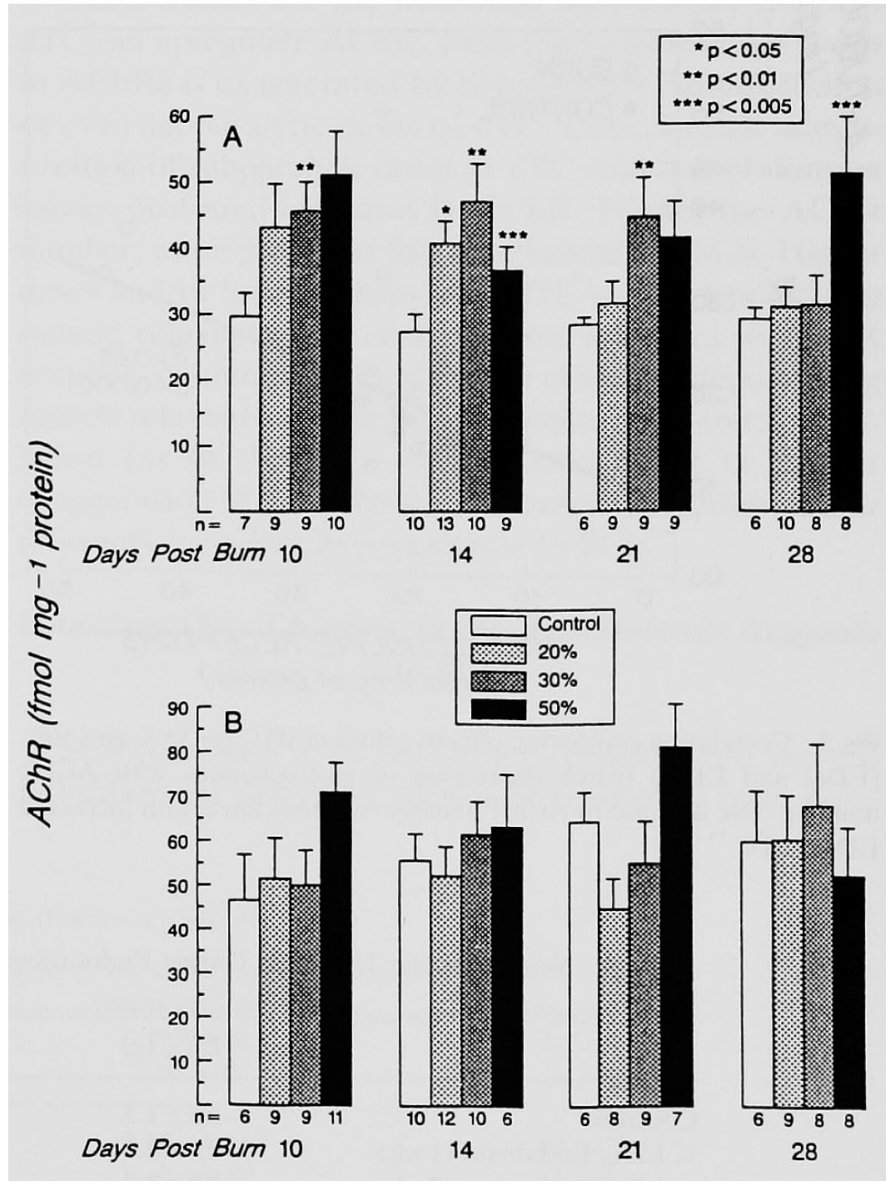

Fig 2 Levels of AChR (fmol.mg ${ }^{-1}$ ) at 10. 14. 21 and 28 days after burn. Column shows mean \pm SEM. Significant increases in AChRs were seen at varying times after burn. 
due to upregulated AChRs. Both dose- and concentrationresponse curves to NDMR are also shifted to the right following immobilization. ${ }^{3}$ Although previous studies of single limb immobilization have documented no lethal hyperkalemic response to $\mathrm{SCh}$, recent studies with bilateral immobilization for 4 weeks have indicated that profound hyperkalemic response to SCh (see below). ${ }^{14}$

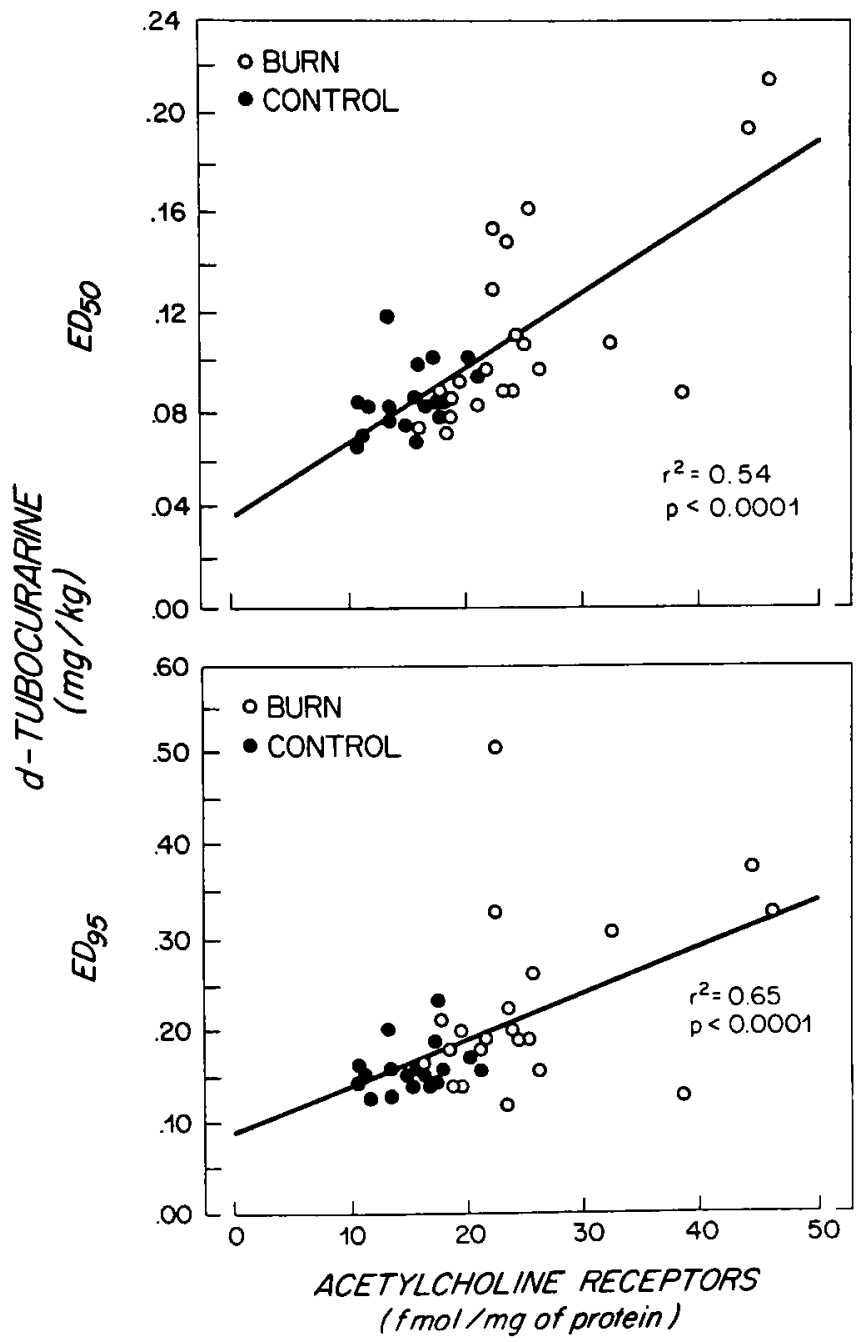

Fig 3 Correlation comparing effective dose of dTC for $95 \%$ and $50 \%$ $\left(E D_{45}\right.$ and $\left.E D_{511}\right)$ twitch depression of gastrocnemius with $A C h R$ number. The increase in $A C h R$ number was associated with increased ED of dTC. ${ }^{11}$

\section{Infection}

Inflammation or infection alters the neuromuscular junction and response to SCh and NDMR. Bacterial toxins such as those released by clostridium (botulinium or tetenus) inhibit the release of $\mathrm{ACh}$ which if prolonged can increase AChRs and cause a denervation-like syndrome. Injection of toxin from E. Coli (endotoxicosis) also has been shown to cause 3 to 5 -fold rightward shift in the dose-response curves to dTC (Table 2). ${ }^{15}$ Weight loss and atrophy, secondary to the effects of toxin, do not appear to be factors, because similar atrophy and weight loss during malnutrition did not reproduce these alterations in response to NDMR. Reinforcement of these observations, relative to infection and muscle relaxants are reports of exaggerated potassium response to $\mathrm{SCh}$ in patients with serious infections of one or more weeks. ${ }^{16}$

\section{Increase of AChRs by NDMRs}

Classical receptor pharmacology suggests that chronic antagonism or inhibition of a receptor will result in upregulation of these receptors. ${ }^{4}$ Although this hypothesis has been tested relative to AChRs, these studies, however, were confounded by the fact that the competitive antagonist simultaneously caused complete or incomplete paralysis of muscles (immobilization). ${ }^{17}$ These investigators, in fact, concluded that immobilization was the cause of the spread of AChRs. The resting membrane potential and input resistance of the muscle fibers that had been paralyzed were similar to those in denervated muscle. ${ }^{17}$

$d T c$ upregulates AChRs in mobile animals: The hypothesis that continuous subluminal (subparalytic) competitive antagonism of AChRs (i.e. antagonism in the absence of immobilization) induces a proliferation of AChRs has been recently tested using dTC as the test drug. ${ }^{19}$ NDMRs could be administered without paralysis because of the high margin of safety of NM transmission. The attendant pharmacodynamic (NM) responses to dTC were also studied. Chronic subparalytic antagonism of $A C h R s$ was achieved in rats by infusion of dTC for 2 weeks through

Table 2 Neuromuscular Dynamics During Endotoxicosis or Malnutrition

\begin{tabular}{lll}
\hline & $\mathrm{E}_{\mathrm{max}}(\mathrm{g})$ & $\mathrm{ED}_{95}(\mathrm{mg} / \mathrm{kg})$ \\
\hline Controls & $59 \pm 1.5$ & $0.08 \pm 0.01$ \\
$1 / 4 \mathrm{LD}_{51}$ Endotoxin $(1 \mathrm{wk})$ & $21 \pm 2.6$ & $0.32 \pm 0.1^{*}$ \\
$1 / 4 \mathrm{LD}_{50}$ Endotoxin $(2 \mathrm{wks})$ & $23 \pm 2.7$ & $0.29 \pm 0.07^{*}$ \\
Protcin Malnutrition (12wks) & $20 \pm 0.3$ & $0.08 \pm 0.03$ \\
\hline
\end{tabular}

* $\mathrm{p}<0.01 ;$ Mean $\pm \mathrm{SE} ;$ Emax $=$ gastrocnemius tension. ${ }^{15}$ 
osmotic mini pumps. No difference in weight gain or mobility was observed between saline or dTC-infused groups. The experimental group was able to develop a baseline tension similar to that of controls (no paralytic effect) despite the presence of plasma dTC concentrations $(0.4 \mu \mathrm{g} / \mathrm{ml})$ that would normally depress twitch to $60 \%$ if administered acutely. These pharmacodynamic alterations were associated with increased extrajunctional AChRs.

dTC accentuates the burn-induced upregulation of AChRs: In more recent studies we have examined whether the administration of a competitive antagonist of the AChR (e.g. dTC) accentuates the upregulation of AChRs induced by burn trauma (Table 4). ${ }^{19}$ The protocol was somewhat similar to that described above, except that dTC was infused directly into the left gastrocnemius. There were no apparent differences in movement eating behavior or weight after implantation of the pumps in burned animals receiving dTC or saline; the presence of withdrawal reflex to pinch confirmed the absence of paralysis even in the dTC-infused group.

The left gastrocnemius AChR numbers (with PE60 tubing placed in close proximity to it) were consistently higher than the contralateral AChRs within the same group. The AChRs on the right and left gastrocnemius in the burn group receiving saline were higher than shaminjured groups, but did not reach statistical significance. The burn group receiving dTC infusion to the left gastrocnemius, however had significant elevations of AChRs

Table 3 Neuromuscular Pharmacodynamics and AChR Changes Following Chronic dTC Infusion

\begin{tabular}{lcc}
\hline \hline & dtC-Exposed & Controls \\
\hline $\begin{array}{l}\text { Junctjional AChRs } \\
\text { (fmole/mg protein) }\end{array}$ & $15.4 \pm 2.1$ & $13.7 \pm 2.0$ \\
$\begin{array}{l}\text { Extrajunctional AChRs } \\
\text { (fmole/mg protein) }\end{array}$ & $19.8 \pm 1.8^{*}$ & $13.4 \pm 1.8$ \\
$\begin{array}{l}\text { dTC concentration for twitch } \\
\text { inhibition }(\mu \mathrm{g} / \mathrm{ml})\end{array}$ & $0.83 \pm 0.04^{*}$ & $0.50 \pm 0.15$ \\
\hline
\end{tabular}

${ }^{*} \mathrm{p}<0.05$ vs controls: values arc Mean $\pm \mathrm{SE} .{ }^{18}$ on that muscle when compared to the ipsilateral muscles of the other two groups.

dTC accentuates immobilization-induced upregulation of AChRs: The effects of immobilization alone, and dTC infusion alone and the combination of the two perturbations on AChR number were tested in separate experiments (in the absence of burn) in the rat. ${ }^{14}$ The role and importance of the immobilization and/or dTC-induced AChR changes on hyperkalemia associated with SCh administration was tested by measuring plasma $\mathrm{K}^{+}$levels at baseline and at 5 minutes following SCh. Bilateral hind limb immobilization was achieved by plaster cast. Four groups of animals were tested (Table 5). Immobilization or dTC infusion alone significantly increased AChR number. The combination of the immobilization with dTC infusion caused the highest AChR proliferation. In all groups, the administration of SCh resulted in significant increases in plasma $\mathrm{K}^{+}$levels. The plasma $\mathrm{K}^{+}$response to $\mathrm{SCh}$, however, was highest following the combination of immobilization and dTC infusion; that is, the hyperkalemia was directly related to $\mathrm{AChR}$ number.

The conclusions that can be made from these dTCinfusion studies are the following: subparalytic doses of dTC can upregulate AChR. Burn injury-induced increases in AChRs is exaggerated by concomitant administration of even subparalytic doses of dTC. Concomitant administration of subparalytic doses of dTC with immobilization causes profound increases in AChR. Higher the AChR number, more profound the hyperkalemia to $\mathrm{SCh}$. Higher doses and/or longer infusions of dTC or nondepolarizing muscle relaxants may cause greater increases in AChR number. Administration of dTC or other nondepolarizing muscle relaxants to patients to facilitate mechanical ventilation (as in the ICU setting) may result in further exaggeration of the aberrant responses to neuromuscular relaxants including hyperkalemia to $\mathrm{SCh}$.

\section{Potassium $\left(\mathrm{K}^{+}\right)$Channels in the Hyperkalemic Response to $\mathrm{SCh}$}

SCh continues to be the drug of choice when there is indication for fast onset of muscle relaxation (e.g. rapid

Table 4 AChRs Following Burns with/without dTC Infusion (fmoles/mg protein)

\begin{tabular}{|c|c|c|c|}
\hline & $\begin{array}{l}\text { Sham Burns with } \\
\text { Saline Infusion } \\
\qquad(\mathrm{n}=10)\end{array}$ & $\begin{array}{c}\text { Burns with Saline } \\
\text { Infusion } \\
(n=9)\end{array}$ & $\begin{array}{l}\text { Burns with dTC } \\
\text { Infusion } \\
(\mathrm{n}=15)\end{array}$ \\
\hline $\begin{array}{l}\text { Left gastrocnemius } \\
\text { right gastrocnemius }\end{array}$ & $\begin{array}{l}\left.7.13 \pm 0.47^{(}\right) \\
5.72 \pm 0.47\end{array}$ & $9.84 \pm 1.21^{(\sigma}$ & $13.93 \pm 07^{\left(\omega^{* * * *} *\right.}$ \\
\hline & & & $7.33 \pm 0.43$ \\
\hline
\end{tabular}


Table 5 Plasma $\mathrm{K}^{+}$Response to SCh and AChR Number in Gastrocnemius Following Immobilization and/or dTC Infusion

\begin{tabular}{|c|c|c|c|c|}
\hline & $\begin{array}{c}\text { Mobilized + } \\
\text { Saline } \\
\text { Infusion }\end{array}$ & $\begin{array}{c}\text { Mobilized + dTC } \\
\text { Infusion }\end{array}$ & $\begin{array}{l}\text { Immobilized + } \\
\text { Saline Infusion }\end{array}$ & $\begin{array}{c}\text { Immobilized + } \\
\text { dTC Infusion }\end{array}$ \\
\hline $\begin{array}{l}\mathrm{K}^{+} \text {Level at Baseline } \\
(\mathrm{MEq} / \mathrm{L})\end{array}$ & 3.4910 .2 & $3.3 \pm 0.2$ & $3.3 \pm 0.3$ & $3.4 \pm 0.2$ \\
\hline $\begin{array}{l}\mathrm{K}^{+} \text {Response to } \mathrm{SCh} \\
(\mathrm{MEq} / \mathrm{L})\end{array}$ & $4.2 \pm 0.2^{*}$ & $5.7 \pm 0.3^{*}$ & $6.5 \pm 0.4^{*}$ & $6.8 \pm 0.4^{*}$ \\
\hline $\begin{array}{l}\text { AChR Number } \\
\text { (fmol/mg Protein) }\end{array}$ & $17 \pm 3$ & $96 \pm 26^{* * *}$ & $233 \pm 29^{* *}$ & $262 \pm 37^{* *}$ \\
\hline
\end{tabular}

${ }^{*} \mathrm{p}<0.05$ compared to baseline values within same group. ${ }^{* *} \mathrm{p}<0.05$ compared to mobile saline group.

intubation, laryngospasm). SCh also has the advantage of short duration of action. As indicated in the previous section many pathological states or iatrogenic factors induce an upregulation of AChRs throughout the muscle membrane. When SCh is administered in the presence of upregulated $\mathrm{AChRs}$, depolarization of the whole muscle membrane occurs which causes massive efflux of $\mathrm{K}^{+}$ from the cell into plasma resulting in potentially lethal hyperkalemia. Both AChRs and $\mathrm{K}^{+}$channels leak $\mathrm{K}^{+}$ from the cell during depolarization. The contribution of potassium channels to the hyperkalemic following $\mathrm{SCh}$ was tested in the following experiments in the denervation model. Potassium channel blockers, 4-aminopyridine (4-AP) and tetraethylammonium (TEA) were used to block the $\mathrm{K}^{+}$channels on the muscle membrane following which $\mathrm{SCh}$ was administered.

After 2 weeks of bilateral sciatic nerve denervation to rats, the plasma $\mathrm{K}^{+}$response to $\mathrm{SCh}(3 \mathrm{mg} / \mathrm{kg})$ was studied. The rise in plasma $\mathrm{K}^{+}$levels induced by $\mathrm{SCh}$ was significantly greater in denervated rats $(2.9 \pm 0.3$ $\mathrm{Mq} / \mathrm{L}, \mathrm{n}=6)$ than on sham-operated controls $(0.7 \pm 0.1$, $\mathrm{n}=6$ ). Pretreatment with either $4-\mathrm{AP}(3$ or $5 \mathrm{mg} / \mathrm{kg}$ ) or TEA $(20$ or $40 \mathrm{mg} / \mathrm{kg}$ ) failed to significantly inhibit the rise in $\mathrm{K}^{+}$. At doses of $60 \mathrm{mg} / \mathrm{kg}$ of TEA attenuation of the hyperkalemia to $\mathrm{SCh}$ was observed $(1.2 \pm 0.3 \mathrm{meq} / \mathrm{L}$, $\mathrm{n}=6, \mathrm{p}<0.05$ ). However at this dose, twitch tension responses were also decreased to $20 \%$ of control response ( $80 \%$ muscle paralysis), suggesting that the inhibition of hyperkalemia was related more to inhibition of AChR ion channel and not the $\mathrm{K}^{+}$channel. These studies, therefore, indicate that $\mathrm{K}^{+}$channels may not play a significant role in the hyperkalemia to SCh. Thus $\mathrm{K}^{+}$ channel blockers may not be clinically useful for the prevention of hyperkalemia to SCh.

\section{Molecular Mechanism of Upregulation of AChRs in Burns}

Expression of $\gamma$-subunit $m R N A$ levels
Burn injury and other critical illnesses are associated with functional and pharmacological changes in skeletal muscle. An important functional change is muscle weakness which results in decreased mobilization, hypoventilation and ventilatory failure. The aberrant pharmacological responses has already been alluded to. It is unclear if the upregulation of AChRs associated with burn injury and critical illnes, although smaller in magnitude, simulates that seen with denervation in terms of expression of immature receptors. With denervation the genes for the immature AChRs are activated where the $\gamma$-subunit substitutes for the $\epsilon$-subunit protein. A smaller single channel conductance and a 2 to 10 fold longer mean open channel time is associated with the immature receptor. Clinical conditions with long mean open channel time are associated with severe muscle weakness and atrophy of muscles. ${ }^{20}$ Slow channel or $\gamma$-type AChRs usually present only in the non-innervated muscle and in congenital slow channel syndromes may be present in burn injury to explain the muscle weakness. In the following molecular biology experiments we have attempted to characterize if increased expression of $\gamma$-subunit AChR occurs following burn injury.

We subjected RNA, isolated from gastocnemius muscle, to Northern Blot analysis with AChR specific cDNA probes. Densitometric analysis of the autoradiograms (normalized to GAPDH mRNA, internal control) indicated significant increases in only the $\alpha$-subunit in muscle from animals with thermal injury but the $\epsilon, \beta$ and $\sigma$ subunit mRNA levels were unchanged (Fig 4). Surprisingly, the expression of the $\gamma$-subunit of the AChR were not diffeent between burned and control groups. It was, however, visualized in the RNA isolated from both embryonic and early postnatal muscle samples, confirming the ability of our cDNA probes to detect $\gamma$-subunit. An additional hallmark of denervation-response in skeletal muscle is a dramatic increase in the expression of transcripts that encode the myogenic regulatory proteins, including myoD and myogenin. RNAs from both control and thermally injured rats were, therefore characterized 


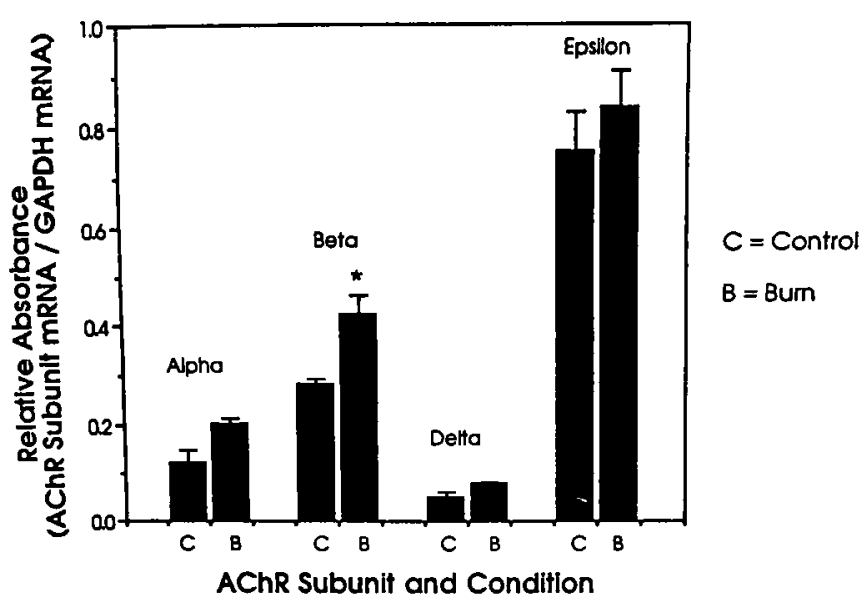

Fig 4 Bar histograms of relative absorbance of $A C h R$ subunit specific mRNAs from gastrocnemius of burned and control animals. Significant increases in $\beta$-subunit mRNA were noted. The myogenic regulatory' proteins myoD and myogenin were unchanged (not shown). ${ }^{21}$

for their expression of myoD which was not altered in burns. These recent findings are consistent with our previous studies. ${ }^{21}$ The absence in changes in myoD and $\gamma$-subunit mRNA levels, thus confirm the absence of a denervation-like state or nerve-mediated cause to account for the proliferation of AChR following burn injury.

\section{Catecholamine-effects on AChRs}

Although catecholamines have been shown to increase breakdown of muscle protein, chronic administration of $\alpha_{2}$-adrenoceptor agonist, clenbuterol, has been shown to decrease protein catabolism and reduce body fat content not only in normal animals, but also in catabolic states such as diabetes, burn injury and muscle denervation. ${ }^{22}$ (Adrenergic receptors of the $\beta_{2}$-type hae been identified in the skeletal muscles of rats and humans.) Because of the association between weight loss (increase protein turnover) and increased AChRs in muscle, prevention of muscle wasting by clenbuterol may prevent some of the functional and pharmacological aberrations associated with burn injury. In the following experiments, using clenbuterol as a catacholamine-agonist and by administering it to normal and burned animals, we also tested the effects of catecholamine-stress on AChRs and expression of AChR subunit transcripts.

The administration of clenbuterol (for 14 days) resulted in a significant enhancement of weight gain in both burned and sham burned animals. AChRs in burned animals were significantly higher than in sham burned animals. The administration of clenbuterol to shamburned animals also resulted in significant increases in AChRs compared to drug-free sham burned animals. Clenbuterol treatment to burned animals resulted in doubling of AChRs relative to other groups. Burn injury alone increased transcripts of $\alpha$-subunit only. The administration of clenbuterol to sham-burn animals did not result in any transcriptional effects. The administration of clenbuterol to burned rats, however, caused a significant expression of $\alpha, \beta, \sigma$ and $\epsilon$ subunit transcripts with no changes in $\gamma$-subunit or in myogenic regulatory proteins myoD and myogenin. These studies, therefore, indicate that clenbuterol has anabolic effects in burned and sham burned rats but does not attenuate $\mathrm{AChR}$ changes of burn trauma. The absence of increase in all subunit mRNA levels or of myogenic regulatory proteins confirms that the upregulation of AChR in burns is not related to a prejunctional, denervation-like phenomenon. Increased translational activity, stability of the receptor, or cAMP-mediated assembly of the receptors may account for the AChR changes in burns. ${ }^{23}$ The concomittant administration of clenbuterol (catecholamine-stress) in association with burn increased the mRNA levels of mature subunits only (no increase in $\gamma$-subunit increase) suggesting that this increase in AChRs may be a genemediated effect.

\section{Downregulation of AChRs}

Decrease of AChRs is a less common phenomenon although it is seen in certain pathological states including myasthenia gravis and chronic cholinesterase inhibition. Hyposensitivity to agonists ( $\mathrm{ACh}$ and $\mathrm{SCh}$ ), and increased

Table 6 Size of Burn, Wet Weights, and AChR Number (Mcan \pm SEM)

\begin{tabular}{|c|c|c|c|c|}
\hline & $\begin{array}{l}\text { Sham-Burn } \\
\text { With No } \\
\text { Clenbuterol } \\
(\mathrm{n}=11)\end{array}$ & $\begin{array}{l}\text { Burns With No } \\
\text { Clenbuterol } \\
(\mathrm{n}=13)\end{array}$ & $\begin{array}{l}\text { Sham-Burn With } \\
\text { Clenbuterol } \\
(\mathrm{n}=10)\end{array}$ & $\begin{array}{l}\text { Burns with } \\
\text { Clenbutcrol } \\
(n=12)\end{array}$ \\
\hline $\begin{array}{l}\text { Burn Size At Day } 0 \\
(\%)\end{array}$ & 0 & $43.3 \pm 1.63$ & 0 & $+2.3 \pm 1.40$ \\
\hline $\begin{array}{l}\text { Wet Weight of } \\
\text { Gastrocnemius (g) }\end{array}$ & $2.13 \pm 0.06$ & $1.54 \pm 0.06^{\text {*..i }}$ & $2.77 \pm 0.08^{*}$ & $1.93 \pm 0.11^{i 1 . c}$ \\
\hline $\begin{array}{l}\text { AChR number } \\
\text { (fmoles/mg protein) }\end{array}$ & $5.57 \pm 0.59$ & $7.29 \pm 0.53^{*}$ & $7.62 \pm 0.64^{*}$ & $1+.27 \pm 1.57^{* a \cdot c c}$ \\
\hline
\end{tabular}


sensitivity to NDMR will be observed (Table 1).

\section{Myasthenia gravis}

Myasthenia gravis is a disorder causing muscle weakness that becomes worse with repeated voluntary activity. Antibodies against AChRs are detectable in about $80 \%$ of patients. ${ }^{24}$ The majority of the antibodies are directed against the AChR and seem to bind to a distinct region on the surface of the AChR subunit, designated the main immunogenic region. The pathophysiology of myasthenia gravis should be contrasted with another auto-immunemediated disease of the neuromuscular junction, namely Lambert-Eaton Myasthenic Syndrome (LEMS) which is a prejunctional phenomenon affecting voltage-gated calcium channel of the nerve terminal.

\section{Chronic cholinesterase inhibition}

The complementary hypothesis, that chronic agonism of $\mathrm{AChR}$ results in down regulation of receptor has also been tested. 3,25 Voltage clamp electrophysiologic techniques and bungarotoxin binding studies have confirmed a reduction in the number of functional AChRs at the neuromuscular junction without affecting channel properties. ${ }^{26}$ Clinical situations in which pathologic elevations of $\mathrm{ACh}$ activity could occur, include an overdose of cholinesterase inhibitors in the treatment of myasthenia gravis, chronic administration of reversable cholinesterase inhibitors as prophylaxis during threat of chemical (nerve) gas warfare, and acute and chronic exposure to organophosphorus insecticude compounds. ${ }^{3,24,27}$

Acknowledgements: This study was partly supported by Grants from NIH RO-1 GM 3156911 and Shrincrs Burns Institute.

\section{References}

1. Selden BS, Curry SC: Prolonged succinylcholine-induced paralysis in organophosphate insecticide poisoning. Ann Emerg Med 1987, 16: $215-217$

2. Dundec JW, Gray TC: Variations in response to relaxant drugs. Lancet 1951, 261: 1015-1018

3. Martyn JA, White DA, Gronert GA, Jaffe RS, Ward JM: Up-and-down regulation of skclctal muscle acctylcholine receptors. Effects on neuromuscular blockers. Anesthesiology 1992. 76: $822-843$

4. Wonnacott S: The paradox of nicotinic acetylcholine receptor up regulation by nicotinc. Trends Pharmacol Sci 1990, 11: 216-219

5. Hall ZW, Sanes JR: Synaptic structure and development: the neuromuscular junction. Cell i993, 72(Suppl): 99-121

6. Gronert GA, Theyc RA: Pathophysiology of hyperkalemia induced by succinylcholine. Anesthesiology 1975, 43: 89-99

7. Goldhill DR, Martyn JA: Succinylcholine-induced hyperkalemia. In: Azar I, ed, Muscle Relaxants: Side Effects and a Rational Approach to Selection, New York, Marcel Dekker, 1987, 93-113
8. Shayevitz JR, Matteo RS: Decreased sensitivity to metocurine in patients with upper motoneuron disease. Anesth Analg 1985, 64: $767-772$

9. Hogue CW Jr, Itani MS, Martyn JA: Resistance to d-Tubocurarine in lower motor neuron injury is related to increased acetylcholine receptors at the neuromuscular junction. Anesthesiology 1990. 73: 703-709

10. Ward JM, Martyn JA: Burn injury-induced nicotinic acetylcholine receptor changes on muscle membrane. Muscle Nerve 1993, 16: 348-354

11. Kim C, Martyn JA, Fuke N: Burn injury to trunk of rat causes denervation-like responses in the gastrocnemius muscle. J Appl Physiol 1988, 65: 1745-1751

12. Pavlin E, Howard M, Slattery JT: Large burns magnify and prolong increases in acetylcholine receptors and resistance to nondepolarizing muscle relaxants in muscle under burned skin in rats. Ancsthcsiology 1994, 81: A1106

13. Perov S, Prasad JK, Nagelhout J, Walczyk M, Martyn JA: Up regulation of acetylcholine in a severely burned patient. Anesthesiology 1994, 81: A1089

14. Yanez P, Itani MS, Martyn JA: D-tubocurarine infusion with and without immobilization causes hyperkalemia to succinylcholine. J Clin Pharmacol (Suppl) 1993, 33: 1007

15. Tomera JF, Martyn JA: Intraperitoneal endotoxin but not protein malnutrition shifts d-tubocurarine dose-response curves in mouse gastrocnemius muscle. J Pharmacol Exp Ther 1989, 250: 216-220

16. Sarubin J, Gebert E: Serumkaliumansteig nach depolarisierenden muskelrelaxantien. I. Abhangigkeit von der Immobilisationsdauer. Anaesthesist 1981, 30: 246-250

17. Berg DK, Hall ZW: Increased extrajunctional acetylcholine sensitivity produced by chronic acetylcholine sensitivity produced by chronic post-synaptic neuromuscular blockade. J Physiol 1975, 244: $569-676$

18. Hogue CW Jr, Ward JM, Itani MS, Martyn JA: Tolerance and upregulation of acetylcholine receptors follow chronic infusion of d-tubocurarine. J Appl Physiol 1992, 72: 1326-1331

19. Martyn JA. Kim C: D-tubocurarine accentuates the burn-induced upregulation of acetylcholine receptors at the muscle membrane. Crit Care Med 1994, 22: A230

20. Engel AG, Hutchinson DO, Nakano S, Murphy L, Griggs RC, Gu Y, Hall ZW, Lindstrom J: Myasthenic syndromes attributed to mutations affecting the epsilon subunit of the acetylcholine receptor. Ann NY Acad Sci 1993, 681: 496-508

21. Ward JM, Rosen KM, Martyn JA: Acetylcholine receptor subunit mRNA changes in burns are different from those seen after denervation: the 1993 Lindberg Award. J Burn Care Rehabil 1993. 14: 595-601

22. Chance WT, Allmen D, Benson D, Zhang FS, Fischer JE: Clenbuterol decrcases catabolism and increaes hypermetabolism in burned rats. J Trauma 1990, 31: 365-370

23. Ross AF, Green WN, Hartmann DS, Claudio T: Efficiency of acetylcholine receptor subunit assembly and its regulation by cAMP. J Cell Biol 1991, 113: 623-636

24. Drachman DB: Myasthenia gravis. N Engl J Med 1994, 330: 1797-1810

25. Fambrough DM, Drachman DB, Satyamurti S: Neuromuscular junction in myasthenia gravis: decreased acetylcholine receptors. Science 1973, 182: 293-295

26. Gwilt M, Wray $\mathrm{D}$ : The effect of chronic neostigmine treatment on channel properties at the rat skeletal neuromuscular junction. Br J Pharmacol 1986, 88: 25-31

27. Keeler JR, Hurst CG, Dunn MA: Pyridostigmine used as a nerve agent pretreatment under wartime conditions. JAMA 1991, 266: $693-695$ 